\title{
Article \\ Symmetrical Antioxidant and Antibacterial Properties of Four Romanian Cruciferous Extracts
}

\author{
Delia Muntean 1,2,3 D, Mariana N. Ştefănuţ ${ }^{4, *}$, Adina Căta ${ }^{4}$, Valentina Buda ${ }^{3,5}$, Corina Danciu ${ }^{3,5}$, Radu Bănică 6 , \\ Raluca Pop 5 (D), Monica Licker ${ }^{1,2}$ (i) and Ioana M. C. Ienaşcu 4,7
}

1 Faculty of Medicine, University of Medicine and Pharmacy “Victor Babes" Timişoara, 2 Eftimie Murgu Square, 300041 Timişoara, Romania; muntean.delia@umft.ro (D.M.); licker.monica@umft.ro (M.L.)

2 Multidisciplinary Research Center on Antimicrobial Resistance,

"Victor Babes" University of Medicine and Pharmacy, 2 Eftimie Murgu Square, 300041 Timişoara, Romania

3 Research Centre for Pharmaco-Toxicological Evaluation,

"Victor Babes" University of Medicine and Pharmacy, 2 Eftimie Murgu Square, 300041 Timişoara, Romania; buda.valentina@umft.ro (V.B.); corina.danciu@umft.ro (C.D.)

4 Department of Chemical and Electrochemical Syntheses, National Institute of Research and Development for Electrochemistry and Condensed Matter, 144 Dr. A. P. Podeanu, 300569 Timişoara, Romania; adina.cata@incemc.ro (A.C.); ioanaienascu@incemc.ro or ienascu.ioana@uvvg.ro (I.M.C.I.)

5 Faculty of Pharmacy, University of Medicine and Pharmacy "Victor Babes" Timişoara, 2 Eftimie Murgu Square, 300041 Timişoara, Romania; pop.raluca@umft.ro

6 Renewable Energy and Electrochemistry Department, National Institute of Research and Development for Electrochemistry and Condensed Matter, 144 Dr. A. P. Podeanu, 300569 Timişoara, Romania; radu.banica@incemc.ro

check for updates

Citation: Muntean, D.; Ştefănuţ, M.N.; Căta, A.; Buda, V.; Danciu, C.; Bănică, R.; Pop, R.; Licker, M.; Ienaşcu, I.M.C. Symmetrical Antioxidant and Antibacterial Properties of Four Romanian Cruciferous Extracts. Symmetry 2021, 13, 893. https://doi.org/10.3390/ sym13050893

Academic Editor: Miroslav Miletín

Received: 12 April 2021

Accepted: 13 May 2021

Published: 18 May 2021

Publisher's Note: MDPI stays neutral with regard to jurisdictional claims in published maps and institutional affiliations.

Copyright: () 2021 by the authors. Licensee MDPI, Basel, Switzerland. This article is an open access article distributed under the terms and conditions of the Creative Commons Attribution (CC BY) license (https:// creativecommons.org/licenses/by/ $4.0 /)$.
7 Department of Pharmaceutical Sciences, Faculty of Pharmacy, "Vasile Goldiş" Western University of Arad, 86 Liviu Rebreanu, 310045 Arad, Romania

* Correspondence: mariana@incemc.ro or mariana.stefanut@gmail.com

\begin{abstract}
Four alcoholic extracts from Romanian Cruciferous species-cabbage, acclimatized broccoli, black radish and cauliflower-were obtained in a microwave field. The extracts showed good and symmetric antioxidant activity (0.97-1.13 mmol/L TE) and good phenolic content (1001-1632 mg GAE/L). For the HPLC method, the limit of detection (LOD), limit of quantitation (LOQ) and recovery degree were established. The small values of LOD and LOQ indicated a great fit of data. The HPLC method achieved satisfactory quantitative recoveries in the range of $96 \%-122 \%$, except for the lowest sinigrin concentration $(8.774 \mu \mathrm{g} / \mathrm{mL})$. The presence of metals in the studied extracts falls within the allowed limits. The four Cruciferous extracts showed good and slightly asymmetric antibacterial activities against some Gram-positive and Gram-negative bacteria, including strains with known resistance to antibiotics. Moreover, greater inhibitory effects were exhibited against Gram-negative bacteria. Asymmetrically, no inhibition was observed on the fungal strains. Therefore, the present results may suggest that some alcoholic extract formulas of cabbage and black radish (presenting good antibacterial activity) might be helpful in the antimicrobial fight and could be successfully used on selected cases and strains.
\end{abstract}

Keywords: cruciferous; antioxidant activities; HPLC; glucosinolates; antibacterial activities

\section{Introduction}

The relationship between food, its therapeutic benefits and medicines dates back to Ancient times when Hippocrates stated the following: "let the food be your medicine and medicine be your food" [1]. As society has evolved, it has started to consume more processed than natural foods, which has led to marked deficiencies in essential nutrients. Therefore, in the latest decades, consumers have tried to compensate for the nutritional deficiencies of food by taking supplements. Nowadays, the current trend has changed, and people have started to value more natural resources rather than to prefer pharmaceuticals because they are better, easily assimilated by the human organism and have 
few side effects [1]. So, several terms have appeared, such as "nutraceutical" or "functional food", as the biologically active substances present in food have similar properties to pharmaceuticals $[1,2]$.

The term "nutraceutical" describes a natural, bioactive substance (cost effective and easily available) that has the ability to induce health-promoting benefits as well as to treat or prevent diseases, apart from its nutritional value [2,3].

Cruciferous vegetables are plants belonging to the Brassicaceae family (commonly known also as Cruciferae family). Brassicaceae is one of the most widely spread and most commonly consumed family of plants. It includes vegetables, such as cabbages, cauliflower, broccoli, as well as oilseed rapeseed and canola [4]. The consumption of cruciferous vegetables can constitute an alternative, healthy diet with a small number of calories and a lot of benefits, being seen as functional foods due to their phytochemical composition. Brassica spp. contain a high quantity of water (around 90\%), a high content of dietary fiber and proteins and a low quantity of carbohydrates for its macronutrients [4]. It contains also micronutrients, such as vitamins (carotenes, tocopherols, vitamin $\mathrm{C}$, folic acid) and minerals (calcium, iron, potassium, phosphorus, sulfur, chlorine and strontium) as well as amino acids. The Cruciferae family contains important secondary metabolites belonging to the phytochemical classes of phenols, polyphenols, phenolic acids, flavonoids (i.e., quercetin and kaempferol), alkaloids, terpenoids, phytosterols, glucosides, and glucosinolates. It possesses also signaling and regulatory compounds, such as phytoalexins, ethylene, salicylic acid, hydrogen peroxide, jasmonic acid and signal peptides [5-10].

For years, Brassicaceae plants have been a fascinating research domain due to their bioactive compounds [11].

Glucosinolates are a group of natural substances located in the plant cells (vacuoles) of seeds, roots, stems and leaves of Cruciferous plants that are not biologically active. They are a class of secondary sulfur-containing metabolites of stress response [4].

Generally, glucosinolates (GLS) are categorized into three major classes: aliphatic, indol, and aromatic glucosinolates [12,13]. To date, more than 120 different GLS have been identified and characterized [6]. The structures of some major GLS found in Brassicaceae spp. are presented in Figure 1. Contents of glucosinolates from Brassicaceae are influenced by factors such as soil, the cultivation and harvesting conditions, climate, and the use of fertilizers and pesticides. Brassicaceae vegetable tissues include one of the major aliphatic glucosinolates [14].
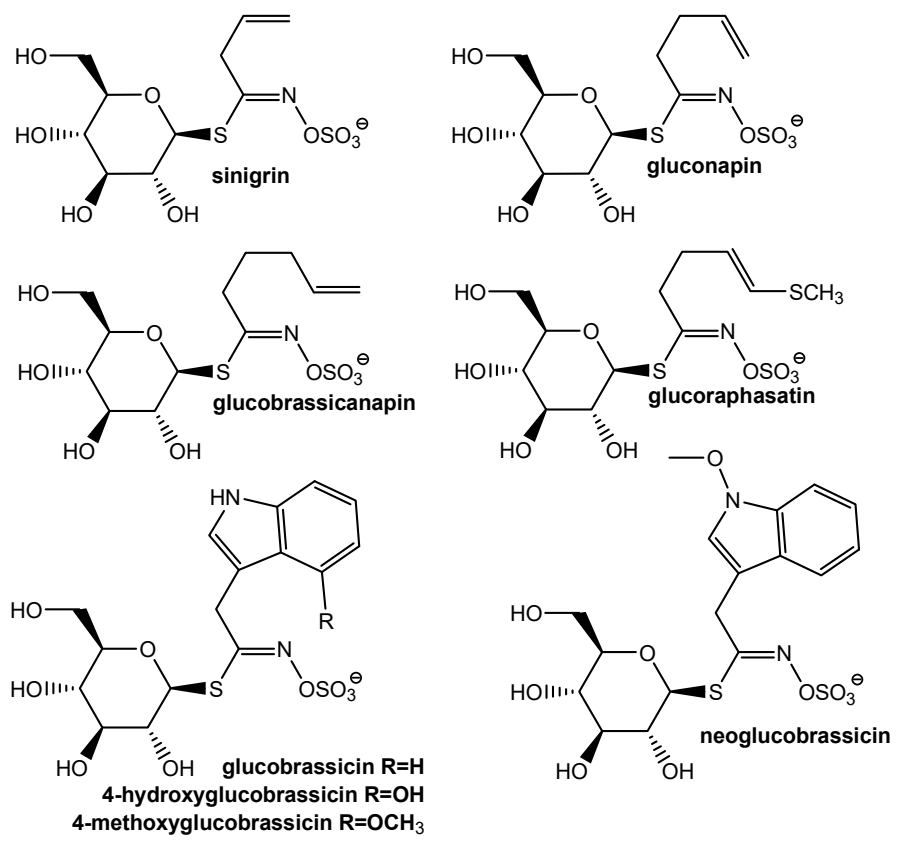

Figure 1. The structures of the GLS compounds commonly found in Brassicaceae spp. 
Glucosinolates and their hydrolysis products are known for their water solubility properties. Glucosinolates are broken down enzymatically by myrosinase (following plant tissue disruption), mainly into isothiocyanates, cyanides and thiocyanates [15].

Accuracy of GLS analysis requires the inactivation of thioglucosideglucohydrolase (myrosinase), an enzyme found in cells in close proximity to glucosinolates, which is responsible for GLS hydrolysis [16]. The hydrolysis products are represented by an unstable aglycone moiety, glucose and sulphate. The aglycones rearrange in the form of isothiocyanates (ITCs), thiocyanates, nitriles, oxazolidinethiones and epithionitriles, depending upon the GLS structure and the conditions of the reaction [8].

Several studies showed that, based on the synergistic action of glucosinolates, polyphenols and triterpenes, cruciferous vegetables have good biological activity, such as those that are anticancer [17], antioxidant [18-20], anti-inflammatory [20,21] and cardioprotective $[4,22]$. Moreover, the glycosylation of triterpenes is one of the plant's defense mechanisms, as it leads to the synthesis of triterpenicsaponins, which has good antimicrobial (antibacterial, antiviral, antifungal) [4,21], antiparasitic, anti-inflammatory and anticancer properties.

Other effects, such as those that are anti-obesity [4], hepatoprotective [20], gastroprotective [23], and immunomodulatory [21], were observed by testing some Brassicaceae extracts.

To fight in the asymmetric war against microbial pathogens by counteracting the resistance of pathogenic bacteria to classical anti-biotherapy, based on the current trend of valuing natural and renewable sources (seen not only in medicine, but also in agriculture and food preservation), the extracts of the cruciferous family could be a safer and also natural alternative to eradicate pathogenic microorganisms $[15,21]$.

Antimicrobial properties of some Cruciferous extracts are demonstrated in the case of both Gram-positive bacteria and in Gram-negative bacteria [4,21] as well as in fungi, so glucosinolates and their breakdown products have been recognized for their benefits for human nutrition, plant defense, and as potent antimicrobial agents [15,24].

The aim of this work is to describe the antioxidant effect, total phenolics, and glucosinolates' HPLC profile of some Romanian cruciferous extracts (CE) and to evaluate the antimicrobial capacity of these extracts against some human pathogens, known to be involved in various infections.

The novelty of this study consists in the high microbial diversity of the tested strains, including resistant bacterial strains, such as methicillin-resistant Staphylococcus aureus (MRSA), extended-spectrum $\beta$-lactamases (ESBL) producing Escherichia coli or carbapenemresistant Pseudomonas aeruginosa.

\section{Materials and Methods}

\subsection{Materials}

1,1-diphenyl-2-picrylhydrazyl (DPPH), 6-hydroxy-2,5,7,8-tetramethylchroman-2carboxylic acid (Trolox), Folin-Ciocalteu reagent, gallic acid (GA), ethanol (EtOH), sulfatase S9692 and DEAE Sephadex A-25, methanol and acetonitrile were all achieved from Merck (Dramstadt, Germany). Romanian vegetables - white cabbage, broccoli, black radish and cauliflower-were purchased from a supermarket in 2019. Ultrapure water was obtained in lab (EASYpureRoDi-Barnstead apparatus, ThermoFisher Scientific, Waltham, MA, USA).

\subsection{Freeze-Drying of Vegetables}

The inactivation of myrosinase was achieved by water elimination using a freezedrying process for vegetables with a new freeze-drying device, projected and developed in our institute. The new type of freeze dryer offers the possibility of attaching and disassembling the frozen material from the cold source using a magnetic coupling. The samples were frozen for $20 \mathrm{~h}$ at $-25^{\circ} \mathrm{C}$ and then lyophilized, maintaining the temperature of the condenser at $-50 \pm 3{ }^{\circ} \mathrm{C}$ during $12-16 \mathrm{~h}$. In the primary drying step, the samples were maintained at a max. temperature of $-5 \pm 2{ }^{\circ} \mathrm{C}$. In the second drying step, the 
samples were heated below $40^{\circ} \mathrm{C}$ for $5 \mathrm{~h}$, using an infrared lamp. Further, they were stored in hermetically sealed containers to prevent water adsorption.

\subsection{Obtaining of Extracts}

The freeze-dried raw materials $(1 \pm 0.0200 \mathrm{~g})$ were subjected to extraction. Extractions of biological active compounds from Romanian cabbage, acclimatized broccoli, black radish and cauliflowers were performed in 70\% ethanol, at a ratio of 10:1 (v/w), using microwave fields in special DAP-60K Teflon vessels (MWS-2 Berghof oven, $2450 \mathrm{MHz}, 120{ }^{\circ} \mathrm{C}, 15 \mathrm{~min}$ ).

Except for the HPLC analyses, for an accurate comparison, the extracts were evaporated under vacuum (Heildolph evaporator) to the same volume $(10 \mathrm{~mL})$.

\subsection{Antioxidant Activity}

The DPPH assay was performed according to the method developed by BrandWilliams et al. [25] with some modifications [26]. A total of $0.1 \mathrm{~mL}$ of extract was added to $2.9 \mathrm{~mL}$ DPPH methanolic solution $(\mathrm{c}=\sim 9.5 \times 10-5 \mathrm{~mol} / \mathrm{L})$ into a glass cuvette. The inhibition of DPPH was followed by monitoring the decrease in absorbance at $515 \mathrm{~nm}$ during $2 \mathrm{~h}$ by using a Jasco 530 spectrofotometer (ABL\&E-JASCO, Wien, Austria). Trolox was used as antioxidant reference compound. The calibration curve was obtained using standard solutions in the range $0.2-1.0 \mathrm{mmol} / \mathrm{L}$ Trolox. Each sample was analyzed in triplicate. The antioxidant activity was expressed as mmol Trolox equivalent per $\mathrm{L}$ of extract (mmol TE/L).

\subsection{Total Phenolics}

The total phenolic content of the cruciferous extracts was determined spectrophotometrically by using the Folin-Ciocalteu method and gallic acid as a reference compound as previously described [26]. A calibration curve (the absorbance at $765 \mathrm{~nm}$ vs. gallic acid solution concentration) was established, using gallic acid solutions in the range of 50-550 mg/L. All extracts were analyzed in triplicate and the results were expressed as $\mathrm{mg}$ gallic acid equivalents per L of extract (mg GAE/L).

\subsection{HPLC Analysis of Glucosinolates}

For HPLC, the extracts were diluted with $70 \%$ ethanol $(200: 1, v / v)$. A total of $1 \mathrm{~mL}$ of each extract containing GLS was treated with $1 \mathrm{~mL}$ DEAE Sephadex A-25 anion exchange resin suspension. A total of $1 \mathrm{~g}$ exchange resin was previously preequilibrated with $10 \mathrm{~mL}$ sodium buffer acetate $(\mathrm{pH}=5.5)$. After retention of GLS on resin, the treatment with the sulphatase solution in microcolumns $(24 \mathrm{~h})$ during $24 \mathrm{~h}$ was achieved. The desulfated glucosinolates (dsGLS) retained on resin were collected with $1 \mathrm{~mL}$ ultrapure water. The GLS standards were also submitted to the desulfation process.

dsGLS were analyzed by the HPLC method using a Dionex Ultimate 3000 (Dionex Corp., Sunnyvale, CA, USA) equipped with a PDA 3000 photodiode array detector and a C-18 Acclaim ${ }^{\circledR} 120$ Silica-Based (Dionex Corp., Sunnyvale, CA, USA) reversed-phase $(4.6 \times 150 \mathrm{~mm}, 5 \mu \mathrm{m})$ at $40{ }^{\circ} \mathrm{C}$ and a flow rate of $0.75 \mathrm{~mL} \cdot \mathrm{min}^{-1}$. The loop injection volume was $20 \mu \mathrm{L}$. A mixture of $5 \%$ acetonitrile and $95 \%$ water as a mobile phase, in isocratic mode, was used. The elution of dsGLS was monitored at $\lambda=230 \mathrm{~nm}$.

\subsection{Analytical Quality Assurance}

The linearity of the calibration curves was studied at a concentration range between 1 and $175 \mu \mathrm{g} / \mathrm{mL}$ for sinigrin and 1 and $300 \mu \mathrm{g} / \mathrm{mL}$ for glucotropaeolin with duplicate injections of a minimum of five standard concentrations.

Limit of detection, LOD and limit of quantitation, LOQ were established using the root mean squared error, RMSE method [27].

$$
\begin{aligned}
& \mathrm{LOD}=3.3 \cdot \sigma / \mathrm{S} \\
& \mathrm{LOQ}=10 \cdot \sigma / \mathrm{S}
\end{aligned}
$$


where $\sigma$ is the standard deviation of the residuals taken from the regression line and $\mathrm{S}$ is the slope of the calibration curve.

In order to determine the degree of analyte recovery, three different concentrations of sinigrin and glucotropaeolin were analyzed in triplicate.

$$
\% \text { Recovery degree }=(\mathrm{EC} / \mathrm{TC}) \cdot 100
$$

Theoretical concentration (TC) of GLS standards represents the concentration of prepared standard solution. Experimental concentration (EC) is the mean concentration of standard solution experimentally determined.

\subsection{Metals Determination}

An AAS spectrophotometer novAA 400G (Analytik Jena, Jena, Germany) equipped with a graphite furnace and autosampler MPE60 and Cookbook for all elements was used in order to determine the concentration of some microelements. The analyses and data were processed with a WinAAS 3.17.0 software. For each element, a calibration curve was previously registered. Calibration solutions were prepared with CertiPUR ${ }^{\circledR}$ standards and ultrapure water (Barnstead, EASYpureRoDi ${ }^{\circledR}$ apparatus, ThermoFisher Scientific, Waltham, MA, USA). The extracts were properly diluted with $0.5 \%$ nitric acid before injection.

\subsection{Antimicrobial Activity Evaluation}

The obtained extracts were first evaporated for ethanol removal and then lyophilized before antimicrobial activity evaluation.

\subsubsection{Bacterial Strains}

A total of 14 bacterial strains and fungus were tested for their susceptibility to the cruciferous extracts (CE). The chosen strains were both reference strains and clinical isolates and they are representative of common human pathogenic bacteria, including strains with resistance to antibiotics. Reference microbial strains tested were represented by Streptococcus mutans ATCC 35668, Streptococcus pyogenes ATCC 19615, Staphylococcus aureus ATCC 25923, Escherichia coli ATCC 25922, Pseudomonas aeruginosa ATCC 27853 and Candida albicans ATCC 10231 (Thermo Scientific, Lenexa, Kansas, USA). The clinical isolates used in this study were obtained from the routine activity of the Clinical Laboratory of the "Pius Brînzeu" Emergency Clinical County Hospital, Timișoara and included methicillin-resistant Staphylococcus aureus (MRSA), Enterococcus faecalis, macrolides-resistant Streptococcus agalactiae, Bacillus cereus, extended-spectrum $\beta$-lactamases (ESBL) producing Escherichia coli, carbapenem-resistant Pseudomonas aeruginosa, Candida parapsilosis and Candida albicans.

\subsubsection{In Vitro Antimicrobial Activity}

The antimicrobial properties for CE were initially evaluated by the disk diffusion method. Then, if any antimicrobial activity was observed, the testing was also performed by the microdilution method according to the Clinical Laboratory and Standard Institute (EUCAST) [28], European Committee on Antimicrobial Susceptibility Testing (EUCAST) [29] and our other studies [30-32].

\subsubsection{Disk Diffusion Method}

At first, all bacteria tested were isolated on Columbia agar $+5 \%$ sheep blood, while for Candida spp. we used Sabouraud Dextrose Agar with Chloramphenicol (bioMérieux, Marcyl'Etoile, France). The microbial suspensions were prepared in $\mathrm{NaCl} 0.85 \%$ (bioMérieux, Marcy-l'Etoile, France) to a concentration of $0.5 \mathrm{McFarland}$, and $100 \mu \mathrm{L}$ of each suspension was inoculated on Mueller-Hinton (MH) agar or MH supplemented with 5\% defibrinated sheep blood (bioMérieux, Marcy-l'Etoile, France). A blank disk (BioMaxima, Lublin, Poland) was placed on the surface of the agar inoculated with microbial suspension and $10 \mu \mathrm{L}$ of $\mathrm{CE}$ were added; then, the plates were incubated for $24 \mathrm{~h}$ at $35-37^{\circ} \mathrm{C}$. Gentamycin $(10 \mu \mathrm{g}$ or $120 \mu \mathrm{g})$ and fluconazole $(25 \mu \mathrm{g})$ disks (BioMaxima, Lublin, Poland) were used for 
the positive control, while the negative control was represented by a blank disk impregnated with $\mathrm{EtOH} \mathrm{70 \% .}$

\subsubsection{Determination of the Minimum Inhibitory Concentrations}

The minimum inhibitory concentrations (MIC) were established by the broth dilution method, using microbial suspensions of $5 \times 10^{5} \mathrm{CFU}$ (colony forming units) $/ \mathrm{mL}$, MH broth or MHF agar, supplemented with defibrinated horse blood $+\beta-\mathrm{NAD}$ and serial dilutions of $\mathrm{CE}$ in $\mathrm{EtOH} 70 \%$ with the following concentrations: 500, 250, 125, 62.5, 31.25, $15.62 \mu \mathrm{g} / \mathrm{mL}$. In six test tubes, $0.1 \mathrm{~mL}$ of each dilution of the CE, $0.4 \mathrm{~mL} \mathrm{MH}$ or MHF broth and $0.5 \mathrm{~mL}$ microbial suspension were added to a final dilution of CE from 50 to $1.56 \mu \mathrm{g} / \mathrm{mL}$. After $24 \mathrm{~h}$ of incubation at $35-37^{\circ} \mathrm{C}$, the lowest concentration of $\mathrm{CE}$ without macroscopically visible growth was considered the MIC.

\subsubsection{Determination of Minimum Bactericidal Concentrations or Minimum} Fungicidal Concentrations

The minimum bactericidal concentrations $(\mathrm{MBC})$ or minimum fungicidal concentrations (MFC) were determined from the last two test tubes that showed no bacterial growth in the broth dilution method. For this, $1 \mu \mathrm{L}$ from these test tubes was inoculated on Columbia agar $+5 \%$ sheep blood or Sabouraud with chloramphenicol and the plates were incubated overnight at $35-37^{\circ} \mathrm{C}$. The MBC/MFC were considered for the concentration where no colonies were developed (concentration which killed $99.9 \%$ of the microbial inoculum).

\section{Results}

According to our previous results (data not shown), the microwave process, using $\mathrm{EtOH}$ $70 \%$, is a good, eco-friendly method of extraction. Four extracts from Romanian cabbage, acclimatized broccoli, black radish and cauliflowers (Figure 2) were obtained and analyzed by UV-Vis technique in order to evaluate their antioxidant effect and total phenolics (Table 1). All analyzed extracts showed good antioxidant activities (0.97-1.13 mmol TE/L).

The results regarding the performance of HPLC method are presented in Tables 2 and 3.

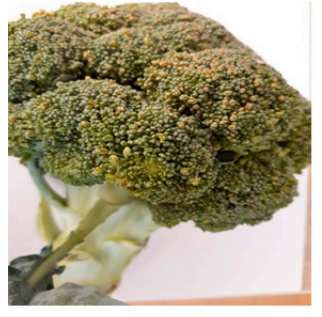

crude broccoli

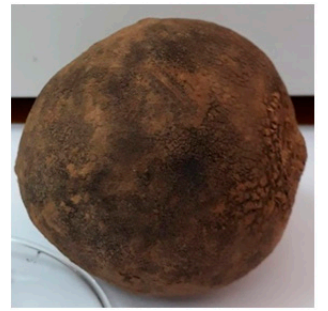

crude black radish

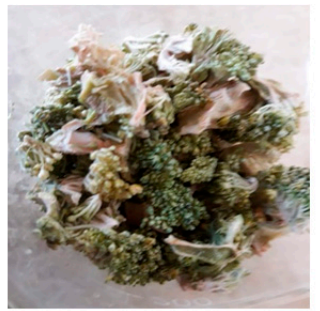

freeze-dried broccoli

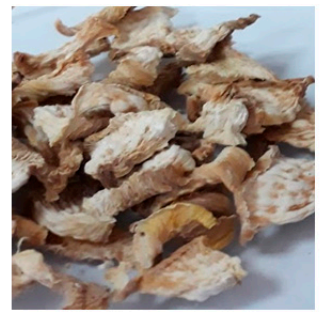

freeze-dried black radish

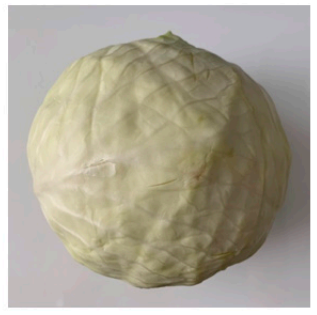

crude cabbage

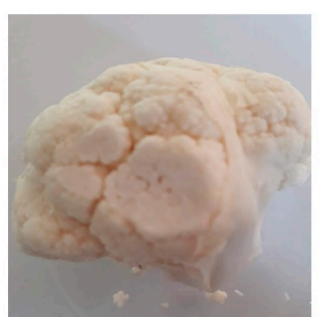

crude cauliflower

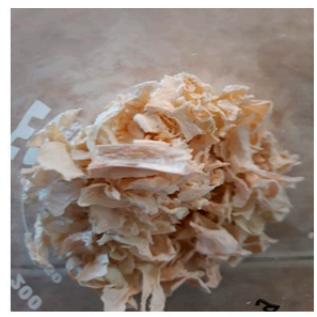

freeze-dried cabbage

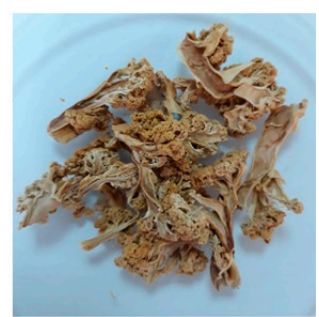

freeze-dried cauliflower

Figure 2. Crude and freeze-dried cruciferous plants. 
Table 1. Antioxidant activity and total phenolics of cruciferous extracts.

\begin{tabular}{cccc}
\hline No. & Extracts & $\begin{array}{c}\text { Antioxidant Activity * } \\
\text { mmol TE/L }\end{array}$ & $\begin{array}{c}\text { Total Phenolics * } \\
\text { mg GAE/L }\end{array}$ \\
\hline 1 & Broccoli & $1.11 \pm 0.01$ & $1632.1 \pm 61.1$ \\
2 & Cabbage & $1.05 \pm 0.05$ & $1001.6 \pm 6.1$ \\
3 & Black radish & $0.97 \pm 0.03$ & $1306.5 \pm 54.5$ \\
4 & Cauliflower & $1.13 \pm 0.06$ & $1394.9 \pm 87.6$ \\
\hline
\end{tabular}

* The results are expressed as mean \pm standard deviation.

Table 2. Standards calibration characterization.

\begin{tabular}{ccccccc}
\hline Analyte & Linear Range, $\mu \mathrm{g} / \mathrm{mL}$ & Calibration Equations & $\mathbf{R}^{\mathbf{2}}$ & $\mathbf{L O D}, \boldsymbol{\mu g} / \mathrm{mL}$ & $\mathbf{L O Q}, \boldsymbol{\mu g} / \mathbf{m L}$ & $\mathbf{t}_{\mathbf{R}}, \mathbf{m i n}$. \\
\hline Sinigrin & $1-175$ & $\mathrm{y}=0.1857 \mathrm{x}+0.2210$ & 0.9995 & 0.43 & 1.31 & 4.6 \\
Glucotropaeolin & $1-300$ & $\mathrm{y}=0.0808 \mathrm{x}+1.9997$ & 0.9942 & 0.87 & 2.65 & 26.1 \\
\hline
\end{tabular}

Table 3. The recovery degree of GLS standards.

\begin{tabular}{|c|c|c|c|c|}
\hline Analyte & $\begin{array}{l}\text { Theoretical Conc. } \\
\text { (TC), } \mu \mathrm{g} / \mathrm{mL}\end{array}$ & $\begin{array}{l}\text { Experimental Conc. } \\
\text { (EC), } \mu \mathrm{g} / \mathrm{mL}\end{array}$ & Recovery, \% & $\begin{array}{c}\text { Recovery, } \\
\text { Mean } \pm \% \text { RSD }\end{array}$ \\
\hline \multirow{9}{*}{ Sinigrin } & \multirow{3}{*}{8.774} & 3.94 & 44.95 & \multirow{3}{*}{$46.97 \pm 10.32$} \\
\hline & & 4.05 & 46.17 & \\
\hline & & 4.37 & 49.79 & \\
\hline & \multirow{3}{*}{43.87} & 53.07 & 120.97 & \multirow{3}{*}{$121.82 \pm 0.69$} \\
\hline & & 53.80 & 122.64 & \\
\hline & & 53.46 & 121.86 & \\
\hline & \multirow{3}{*}{175.48} & 176.40 & 100.53 & \multirow{3}{*}{$101.25 \pm 0.62$} \\
\hline & & 178.47 & 101.71 & \\
\hline & & 178.13 & 101.51 & \\
\hline \multirow{9}{*}{ Glucotropaeolin } & \multirow{3}{*}{50} & 49.71 & 99.41 & \multirow{3}{*}{$97.19 \pm 2.01$} \\
\hline & & 48.21 & 96.42 & \\
\hline & & 47.87 & 95.73 & \\
\hline & \multirow{3}{*}{100} & 107.76 & 107.76 & \multirow{3}{*}{$106.42 \pm 1.09$} \\
\hline & & 105.75 & 105.75 & \\
\hline & & 105.75 & 105.75 & \\
\hline & \multirow{3}{*}{300} & 293.01 & 97.67 & \multirow{3}{*}{$96.52 \pm 1.06$} \\
\hline & & 288.45 & 96.15 & \\
\hline & & 287.23 & 95.74 & \\
\hline
\end{tabular}

The values obtained for the correlation coefficients $(>0.994)$ prove very good linearity of the method.

In order to evaluate the precision of the HPLC method, the limit of detection (LOD) and the limit of quantitation (LOQ) were established. The results for LOD and LOQ are presented in Table 2. The lower values of LOD and LOQ indicate a better fit of data.

The retention time of desulfated GLS standards was registered around $t_{R}=4.6 \mathrm{~min}$ (sinigrin) and $t_{R}=26.1 \mathrm{~min}$ (glucotropaeolin).

The recovery degree (Table 3) was studied for sinigrin and glucotropaeolin. The obtained results demonstrated that the method achieved satisfactory quantitative recoveries in the range of $96 \%-122 \%$, except for the recovery degree for the lowest sinigrin concentration $(8.774 \mu \mathrm{g} / \mathrm{mL})$.

On a reverse-phase C18 column, sinigrin, gluconapin and glucobrassicanapin formed an eluotropic series of alkenyl glucosinolates [33]. The literature data showed that glucobrassicanapin eluted before glucobrassicin [34] and neoglucobrassicin eluted later than the isomer methoxy-glucobrassicin $[35,36]$. The assignment of eluted glucosinolates was assumed on the retention time of the available standards and literature data. 
Figure 3 shows the chromatographic profile of studied vegetable extracts. The retention time of the important peaks is presented in Table 4 . The concentration of sinigrin decreases as follows: cauliflower $(11.45 \mu \mathrm{g} / \mathrm{mL})>$ black radish $(10.68 \mu \mathrm{g} / \mathrm{mL})>$ cabbage $(3.44 \mu \mathrm{g} / \mathrm{mL})>$ broccoli $(2.60 \mu \mathrm{g} / \mathrm{mL})$. Glucotropaeolin was not detected in the studied extracts.
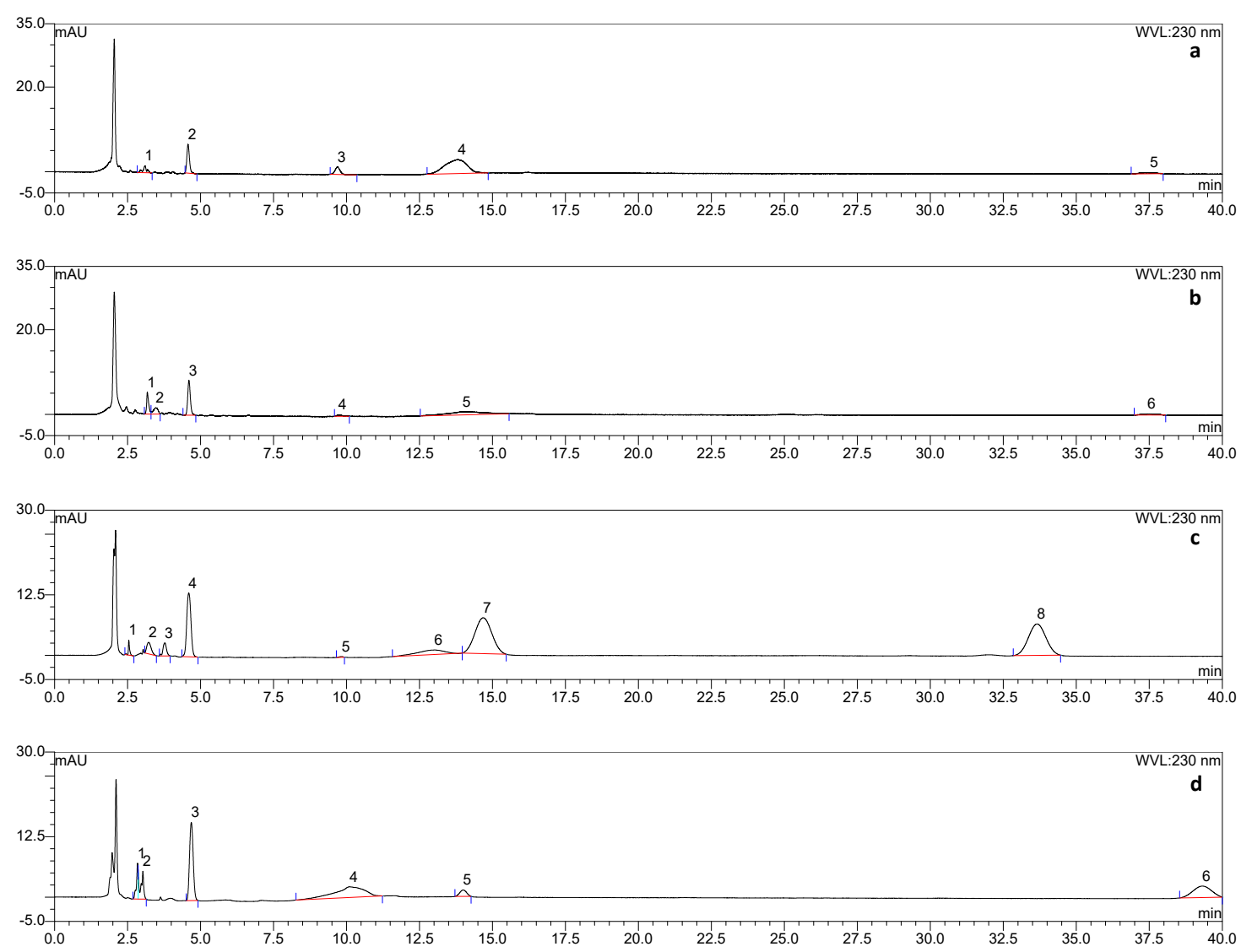

Figure 3. Chromatographic profiles of cruciferous vegetables: (a) broccoli; (b) cabbage; (c) black radish; (d) cauliflower.

Table 4. Retention time of important peaks.

\begin{tabular}{ccc}
\hline Sample & Compound & Retention Time, $\left.\mathbf{t}_{\mathbf{R}} \mathbf{( m i n}.\right)$ \\
\hline \multirow{3}{*}{ Broccoli } & peak 1 & 3.093 \\
& peak 2 (sinigrin) & 4.574 \\
& peak 3 & 9.693 \\
& peak 4 & 13.819 \\
& peak 5 & 37.527 \\
\hline \multirow{3}{*}{ Cabbage } & peak 1 & 3.178 \\
& peak 2 & 3.468 \\
& peak 3 (sinigrin) & 4.603 \\
& peak 4 & 9.727 \\
& peak 5 & 13.972 \\
& peak 6 & 37.435 \\
\hline \multirow{3}{*}{ Black radish } & peak 1 & 2.544 \\
& peak 2 & 3.225 \\
& peak 3 & 3.778 \\
& peak 4 (sinigrin) & 4.598 \\
& peak 5 & 9.839 \\
& peak 6 & 13.008 \\
& peak 7 & 14.679 \\
& peak 8 & 33.653 \\
\hline
\end{tabular}


Table 4. Cont.

\begin{tabular}{ccc}
\hline Sample & Compound & Retention Time, $\mathbf{t}_{\mathbf{R}}(\mathbf{m i n}$.) \\
\hline & peak 1 & 2.845 \\
& peak 2 & 3.027 \\
Cauliflower & peak 3 (sinigrin) & 4.685 \\
& peak 4 & 10.108 \\
& peak 5 & 13.996 \\
& peak 6 & 39.319 \\
\hline
\end{tabular}

The metal concentrations in the tested vegetables are presented in Table 5.

Table 5. Metal concentrations in tested vegetables (AAS).

\begin{tabular}{ccccccccccc}
\hline \multirow{2}{*}{ Sample } & \multicolumn{8}{c}{ Metal Concentration ${ }^{*}, \boldsymbol{\mu g} / \mathbf{g}$ Dried Material } \\
\cline { 2 - 10 } & As & Cd & Cr & Pb & Zn & Cu & Mn & Fe & Co & Se \\
\hline Broccoli & - & - & - & - & $54.2 \pm 3.3$ & $4.0 \pm 0.2$ & $0.6 \pm 0.07$ & $113.0 \pm 40$ & - & - \\
Cabbage & - & - & - & - & $42.1 \pm 2.1$ & $2.7 \pm 0.3$ & $0.7 \pm 0.007$ & $99.3 \pm 41$ & - & - \\
Black radish & - & - & - & - & $21.6 \pm 0.8$ & $2.1 \pm 0.1$ & $0.26 \pm 0.0$ & $339.5 \pm 7$ & - & - \\
Cauliflower & - & - & - & - & $32.0 \pm 1.7$ & $0.9 \pm 0.1$ & $1.19 \pm 0.0$ & $159.3 \pm 11$ & - & - \\
\hline
\end{tabular}

* The results are expressed as mean \pm standard deviation.

Microelements such as zinc, copper, manganese, and iron, are known for their health benefits. The presence of these elements in our extracts falls within the allowed limits [37].

Very large quantities of $\mathrm{Zn}(21-55 \mu \mathrm{g} / \mathrm{g})$ and $\mathrm{Fe}(99-340 \mu \mathrm{g} / \mathrm{g})$ were registered in broccoli and black radish, respectively. The studied extracts do not contain $\mathrm{As}, \mathrm{Cd}$, and $\mathrm{Pb}$, according to the Directive 2002/32/EC [38].

The antimicrobial activity of the four cruciferous extracts (CE) are shown in Table 6.

Table 6. Antimicrobial activity of lyophilized extracts.

\begin{tabular}{|c|c|c|c|c|}
\hline Sample Extracts & Bacterial Strains & $\begin{array}{l}\text { Disk Diffusion Method } \\
\text { (Inhibition Zones), mm * }\end{array}$ & $\mathrm{MIC}^{* *}, \mu \mathrm{g} / \mathrm{mL}$ & $\mathrm{MBC}^{* * *}, \mu \mathrm{g} / \mathrm{mL}$ \\
\hline \multirow{14}{*}{ White cabbage } & Streptococcus mutans ATCC 35668 & $15.67 \pm 0.58$ & 12.5 & 50 \\
\hline & Streptococcus pyogenes ATCC 19615 & $17.33 \pm 1.15$ & 12.5 & 50 \\
\hline & Staphylococcus aureus ATCC 25923 & $15.67 \pm 0.58$ & 12.5 & 50 \\
\hline & Escherichia coli ATCC 25922 & $18.0 \pm 1.73$ & 6.25 & 25 \\
\hline & Pseudomonas aeruginosa ATCC 27853 & $15.33 \pm 0.58$ & 6.25 & 25 \\
\hline & Candida albicans ATCC 10231 & $7.67 \pm 1.15$ & - & - \\
\hline & Staphylococcus aureus (clinical isolate) & $16.0 \pm 1$ & 12.5 & 50 \\
\hline & Enterococcus faecalis (clinical isolate) & $15.33 \pm 0.58$ & 12.5 & 50 \\
\hline & Streptococcus agalactiae (clinical isolate) & $16.0 \pm 1.0$ & 12.5 & 50 \\
\hline & Escherichia coli (clinical isolate) & $18.67 \pm 0.58$ & 6.25 & 25 \\
\hline & Pseudomonas aeruginosa (clinical isolate) & $15.67 \pm 0.58$ & 6.25 & 25 \\
\hline & Bacillus cereus (clinical isolate) & $17.33 \pm 1.15$ & 12.5 & 50 \\
\hline & Candida parapsilosis (clinical isolate) & $7.0 \pm 0.0$ & - & - \\
\hline & Candida albicans (clinical isolate) & $7.0 \pm 0.0$ & - & - \\
\hline \multirow{14}{*}{ Black radish } & Streptococcus mutans ATCC 35668 & $16.0 \pm 0.0$ & 12.5 & 50 \\
\hline & Streptococcus pyogenes ATCC 19615 & $17.33 \pm 0.58$ & 12.5 & 50 \\
\hline & Staphylococcus aureus ATCC 25923 & $16.33 \pm 0.58$ & 12.5 & 50 \\
\hline & Escherichia coli ATCC 25922 & $18.33 \pm 0.58$ & 6.25 & 12.5 \\
\hline & Pseudomonas aeruginosa ATCC 27853 & $16.0 \pm 0.0$ & 6.25 & 25 \\
\hline & Candida albicans ATCC 10231 & $8.33 \pm 1.15$ & - & - \\
\hline & Staphylococcus aureus (clinical isolate) & $15.66 \pm 0.58$ & 12.5 & 50 \\
\hline & Enterococcus faecalis (clinical isolate) & $15.0 \pm 0.0$ & 12.5 & 50 \\
\hline & Streptococcus agalactiae (clinical isolate) & $16.67 \pm 0.58$ & 12.5 & 50 \\
\hline & Escherichia coli (clinical isolate) & $19.0 \pm 0.0$ & 6.25 & 12.5 \\
\hline & Pseudomonas aeruginosa (clinical isolate) & $15.33 \pm 0.58$ & 6.25 & 25 \\
\hline & Bacillus cereus (clinical isolate) & $17.0 \pm 0.0$ & 12.5 & 50 \\
\hline & Candida parapsilosis (clinical isolate)) & $7.0 \pm 0.0$ & - & - \\
\hline & Candida albicans (clinical isolate) & $7.0 \pm 0.0$ & - & - \\
\hline
\end{tabular}


Table 6. Cont.

\begin{tabular}{|c|c|c|c|c|}
\hline Sample Extracts & Bacterial Strains & $\begin{array}{l}\text { Disk Diffusion Method } \\
\text { (Inhibition Zones), mm * }\end{array}$ & $\mathrm{MIC}^{* *}, \mu \mathrm{g} / \mathrm{mL}$ & $\mathrm{MBC}^{* * *}, \mu \mathrm{g} / \mathrm{mL}$ \\
\hline \multirow{14}{*}{ Cauliflower } & Streptococcus mutans ATCC 35668 & $15.0 \pm 0.0$ & 50 & - \\
\hline & Streptococcus pyogenes ATCC 19615 & $15.33 \pm 0.58$ & 50 & - \\
\hline & Staphylococcus aureus ATCC 25923 & $14.67 \pm 0.58$ & 50 & - \\
\hline & Escherichia coli ATCC 25922 & $15.67 \pm 0.58$ & 50 & - \\
\hline & Pseudomonas aeruginosa ATCC 27853 & $15.0 \pm 0.0$ & 50 & - \\
\hline & Candida albicans ATCC 10231 & $7.33 \pm 0.58$ & - & - \\
\hline & Staphylococcus aureus (clinical isolate) & $15.33 \pm 0.58$ & 50 & - \\
\hline & Enterococcus faecalis (clinical isolate) & $14.0 \pm 0.0$ & 50 & - \\
\hline & Streptococcus agalactiae (clinical isolate) & $15.0 \pm 0.0$ & 50 & - \\
\hline & Escherichia coli (clinical isolate) & $16.0 \pm 0.0$ & 50 & - \\
\hline & Pseudomonas aeruginosa (clinical isolate) & $15.33 \pm 0.58$ & 50 & - \\
\hline & Bacillus cereus (clinical isolate) & $15.67 \pm 0.58$ & 50 & - \\
\hline & Candida parapsilosis (clinical isolate) & $7.0 \pm 0.0$ & - & - \\
\hline & Candida albicans (clinical isolate) & $7.0 \pm 0.0$ & - & - \\
\hline \multirow{14}{*}{ Broccoli } & Streptococcus mutans ATCC 35668 & $15.33 \pm 0.58$ & 50 & - \\
\hline & Streptococcus pyogenes ATCC 19615 & $15.67 \pm 0.58$ & 50 & - \\
\hline & Staphylococcus aureus ATCC 25923 & $15.0 \pm 0.0$ & 50 & - \\
\hline & Escherichia coli ATCC 25922 & $16.0 \pm 0.0$ & 25 & - \\
\hline & Pseudomonas aeruginosa ATCC 27853 & $15.0 \pm 0.0$ & 50 & - \\
\hline & Candida albicans ATCC 10231 & $7.33 \pm 0.58$ & - & - \\
\hline & Staphylococcus aureus (clinical isolate) & $15.33 \pm 0.58$ & 50 & - \\
\hline & Enterococcus faecalis (clinical isolate) & $14.67 \pm 0.58$ & 50 & - \\
\hline & Streptococcus agalactiae (clinical isolate) & $15.0 \pm 0.0$ & 50 & - \\
\hline & Escherichia coli (clinical isolate) & $16.33 \pm 0.58$ & 25 & - \\
\hline & Pseudomonas aeruginosa (clinical isolate) & $11.50 \pm 0.0$ & 50 & - \\
\hline & Bacillus cereus (clinical isolate) & $15.33 \pm 0.58$ & 50 & - \\
\hline & Candida parapsilosis (clinical isolate) & $7.0 \pm 0.0$ & - & - \\
\hline & Candida albicans (clinical isolate) & $7.0 \pm 0.0$ & - & - \\
\hline
\end{tabular}

* The results are expressed as mean \pm standard deviation; ${ }^{* *}$ MIC-Minimum Inhibitory Concentration; ${ }^{* * *}$ MBC-Minimum Bactericidal Concentration; Observation: over $15 \mathrm{~mm}$-good antimicrobial activity; $13-15 \mathrm{~mm}$-moderate antimicrobial activity; under $12 \mathrm{~mm}$ - poor or zero antimicrobial activity.

The antimicrobial activity of the CEs evaluated by disk diffusion method was interpreted according to the sensitivity criteria for positive control.

Most bacterial strains presented symmetric, moderate sensitivity to the cauliflower or broccoli extracts and were symmetrically more sensitive to white cabbage and black radish compounds for which the bactericidal effects were also highlighted. In addition, for those two extracts, the values of MBC were higher than those of MIC. Moreover, for the white cabbage and black radish extracts the antimicrobial effect on Gram-negative bacteria was slightly higher than that for the Gram-positive. Antifungal activity was not observed for any of the CEs in an asymmetrical way, compared to the antibacterial activity of the same compounds.

\section{Discussion}

Cruciferous vegetables are a rich source of dietary antioxidants $[39,40]$. However, the antioxidants content in different Brassica vegetables can be influenced by various factors, such as climatic conditions, agricultural practices, genotype, storage conditions, etc. [41], leading to different results as reported in the literature.

There is convincing evidence that GSLs act against the damaging effects of free radicals both directly and indirectly. Some researchers reported that GSLs are unlikely to have direct antioxidant activity [42]. Others reported that some GLSs, such as glucoerucin and its metabolite, are hydroperoxide scavenging antioxidants, and glucoraphasatin possesses a reducing capacity against $\mathrm{H}_{2} \mathrm{O}_{2}$ and $\mathrm{ABTS}^{*+}$ radical cations, thus proving good, direct antioxidant activity [43].

The extracts studied in this research showed good antioxidant capacities, the best values being obtained for cauliflower and broccoli. These two extracts exhibited also great polyphenolic content (Table 1). The chromatographic separation of intact GLSs was 
historically a technical challenge that required several techniques because of the poor retention of GLSs with hydrophilic side chains [36].

The sulfate group of GLS can be removed by the addition of a sulfatase, and the obtained dsGLS can be eluted with water so that a higher content of GLS is gained. Furthermore, dsGLS are more easily retained on standard C18 HPLC columns than intact GLS. The evaluation of the GLS profile can be assessed using a UV or MS analysis. The choice between these two possibilities depends on the available equipment. Depending on the purpose, i.e., quantification (dynamic range, lower limit of quantification), the analysis should be carried out on dsGLS [16].

Many researchers have described the glucosinolates profile of different Brassica vegetables. Despite the fact that they are all part of the same species, the glucosinolates profile vary for each type of cruciferous vegetable [44]. All different types of Brassica oleracea contain glucobrassicin and glucoiberin. In cabbage, glucobrassicin, glucoiberin and sinigrin have been identified as the major glucosinolates [45]. In the current study, sinigrin was found as the predominant glucosinolate in the cabbage extract. Hwang et al. [46] found that glucoerucin and glucobrassicin were the most abundant GLS in cabbage and broccoli. In broccoli, common glucosinolates are glucoraphanin, sinigrin, progoitrin, gluconapin, glucobrassicin and neoglucobrassicin. More than $50 \%$ of the total glucosinolates is glucoraphanin, while sinigrin is found in small amounts [45]. Other authors have also found that glucoraphanin is the predominant glucosinolate in broccoli [47]. Vicas et al. [48] reported high levels of glucosinolates in broccoli, glucoraphanin, glucobrassicin and neoglucobrassicin being the major components. We found that broccoli contains sinigrin (peak 2); other peaks could be assigned as gluconapin (peak 3), glucobrassicin (peak 4) and methoxyglucobrassicin (peak 5) [33]. Tian et al. [47] also found high amounts of methoxyglucobrassicin in broccoli. On the other hand, Vicaș et al. [48] reported no content of sinigrin and gluconapin in broccoli extracts. The main glucosinolates reported in cauliflower extracts were sinigrin, glucoiberin, and glucobrassicin [49]. Additionally, sinigrin and glucoiberin were reported as the major GLSs in cauliflower [48]. Sinigrin (peak 3) was found in cauliflower extract; other peaks could be assigned as gluconapin (peak 4), glucobrassicin (peak 5) and neoglucobrassicin (peak 6), with peak 6 being the major glucosinolate.

Kim et al. [50] found significantly different levels of 13 GSLs in both the skin and flesh of some radish cultivars. Glucoraphanin, glucobrassicin, methoxyglucobrassicin, and glucoraphasatin were present in both the skin and the flesh of all samples. The glucosinolates profile of black radish dietary supplements has been investigated by Ediage et al. [51], and six glucosinolates (glucoraphasatin, glucosisaustricin, glucoraphenin, glucoputrajivin, glucosisymbrin and gluconasturtiin) were identified. Our black radish extract showed the presence of eight compounds, with the last two being the most predominant. Sinigrin appears in chromatogram at $4.598 \mathrm{~min}$. Peaks 5 and 6 could be assigned as gluconapin and glucobrassicanapin [33], while peaks 7 and 8 could be 4-hydroxyglucobrassicin and glucoraphasatin [50]. However, some authors [33] reported that 4-hydroxyglucobrassicin eluted before glucobrassicanapin.

The interest in finding new alternatives to classical antibiotics is mandatory, as bacterial multidrug resistance has become an important public health issue. Natural extracts with low degrees of unfavorable effects may become trustworthy alternatives in antimicrobial combat as are, for example, essentials oils against multidrug-resistant bacteria involved in hospital-acquired infections [31,52,53].

It is already known that antimicrobials, which are derived from plants, are usually secondary metabolites [15]. Glucosinolates and their enzymatic hydrolysis products are among the most potent plant-derived antimicrobials. Moreover, the biocidal effect of cruciferous plants has been linked primarily to the volatile degradation substances of GLS. Isothiocyanates (synthetized after the enzymatic hydrolysis) are volatile substances known as the dominant inhibitors of microbial activity [15].

Sinigrin is a GLS that is hydrolyzed by myrosinase (either after injury or mechanical disruption) in allylisothiocyanate (AITC), allylthiocyanate (ATC), allyl cyanide (AC) and 
other products. Several studies highlighted that sinigrin presents low effects on the growth of microorganisms, compared with its hydrolysis substances, which present a more potent inhibitory effect on the growth of microorganisms [54]. Among sinigrin's hydrolysis products, allylisothiocianates induced the highest antibacterial activity (MIC against Gramnegative and Gram-positive non-lactic acid bacteria: 100-200 ppm; MIC against lactic acid bacteria 500-1000 ppm) [15,54].

Kyung et al. [55] tested sinigrin and its hydrolysis products on 15 species of bacteria, with MICs varying from 50-500 ppm for Gram-positive, Gram-negative or lactic acid bacteria.

Dias et al. [56] showed in 2014 that several purified hydrolysis products obtained from cruciferous vegetables, including AITC, showed the highest antimicrobial activity against 15 strains of methicillin-resistant $S$. aureus, isolated from patients with diabetic ulcers.

The results of the present research are in concordance with other performed studies, which showed that some CE had greater inhibitory effects against Gram-negative bacteria than against Gram-positive bacteria [21].

A study performed by Jadoun et al. [57], in 2016, showed a new compound in red radish seeds (ethanol extract) with potent antimicrobial activity (on S. pyogenes and E. coli, MIC: $0.5-1 \mathrm{mg} / \mathrm{mL}$ ) in the presence of [5-methylsulfinyl-1-(4-methylsulfinyl- but-3-enyl)pent-4-enylidene]-sulfamic acid. The newly identified compound contains two identical sulfur side chains, comparable to those from ITCs.

White radish ethanolic extract showed the highest antibacterial activity against $P$. aeruginosa, with a MIC and MBC of $15 \mu \mathrm{g} / \mathrm{mL}$ [58].

The study performed by Rubab et al. [59] on white cabbage extracts in 2020 showed that they induced medium to low in vitro activity against all tested microorganisms, with higher activity against Gram-positive bacteria, compared with Gram-negative bacteria. Moreover, the extracts reduced the growth of several fungi strains (including C. albicans), but with lower activity compared with the one on the bacterial strains.

All the studies that were performed highlighted the effectiveness of GLS also as food preservatives, being potent also against plant pathogenic microorganisms $[11,60,61]$. Moreover, they presented a synergistic effect when associating with classical antibiotics [62].

The mechanism of action of ITC's antimicrobial activity has not been fully elucidated and several hypotheses are available for the moment. One of them states that the ITC's central electrophilic carbon $(\mathrm{R}-\mathrm{N}=\mathrm{C}=\mathrm{S})$, after undergoing rapid reactions with hydroxyls, thiols and amines, will form products, such as carbamates, thiocarbamates and thiourea. AITC will later react with glutathione, proteins, water, alcohol, sulfites and amino acids, leading to the disintegration of cysteine disulfide bounds (by an oxidative process) $[63,64]$.

Borges et al. [65] demonstrated that allylisothiocyanate (AITC) and 2-phenylethylisothiocyanate (PEITC) affect the cytoplasmatic membrane, decreasing the surface charge, and altering the hydrophobicity, thereby damaging its integrity, followed by potassium leakage and propidium iodide assimilation.

On the other hand, the lower activity of CE against Gram-positive bacteria could be attributed to their structures and the presence of pores only in the Gram-negative bacteria wall [21].

While Zampini et al. [66] stated that ethanol-water extract was the best solvent for the extraction of active compounds, $\mathrm{Hu}$ et al. [21] proved that, from various extracts of crucifers, crude protein extracts exhibited the greatest antimicrobial effects compared with water extracts and methanol-water extracts.

\section{Conclusions}

The extracts of Brassicacae Romanian vegetables demonstrated good antioxidant activity and rich phenolic contents. Additionally, they are sources of nutritive microelements, such as $\mathrm{Fe}, \mathrm{Cu}, \mathrm{Zn}, \mathrm{Mn}$. No toxic metals, such as $\mathrm{As}, \mathrm{Cd}$ and $\mathrm{Pb}$, were registered.

For the separation of desulfated glucosinolates, an HPLC method was developed on a Dionex system. The C-18 Acclaim ${ }^{\circledR} 120$ column may be used for common glucosinolate 
separation (alkenyl derivatives, especially). On the other hand, the lack of some specific standards added difficulties in the quantification process.

The present results may suggest that some alcoholic extract formulas of cabbage and black radish (presenting good antibacterial activity) may be helpful in antimicrobial combat and could be, therefore, used for selected cases and strains.

Moreover, we can hypothesize the possible use of these extracts as new therapeutical options for resistant bacteria. Beneficial results could be obtained by the use of these extracts as topical treatment (i.e., ointments).

However, this research field remains open to finding the proper ways of delivering the active antimicrobial compounds to the site of action.

Author Contributions: Conceptualization, C.D., M.N.Ș., A.C. and I.M.C.I.; methodology, M.N.S,., R.B., D.M., M.L. and C.D.; software, A.C.; validation, M.N.Ș., D.M., C.D., V.B., R.P. and M.L.; formal analysis, M.N.S., A.C., D.M. and M.L.; investigation, D.M., M.L., M.N.S., A.C., I.M.C.I., V.B., C.D. and R.P.; resources, D.M., M.N.S., A.C., V.B., C.D., R.B., R.P., M.L. and I.M.C.I.; data curation, D.M., M.N.S., C.D., A.C. and V.B.; writing-original draft preparation, M.N.Ș., D.M., A.C., I.M.C.I. and C.D.; writing—review and editing, A.C., D.M. and M.N.S.; visualization, D.M. and M.N.S.; supervision, D.M. and M.N.S. All authors have read and agreed to the published version of the manuscript.

Funding: This research was funded by the University of Medicine and Pharmacy "Victor Babes", Eftimie Murgu Square, No. 2, 300041 Timisoara, România. Some experiments were also performed at the National Institute of Research and Development for Electrochemistry and Condensed Matter Timisoara.

Institutional Review Board Statement: Not applicable.

Informed Consent Statement: Not applicable.

Data Availability Statement: Supplementary data regarding the present manuscript is available under request from the corresponding author.

Conflicts of Interest: The authors declare no conflict of interest.

\section{References}

1. Dudeja, P.; Gupta, R.K. Chapter 40-Nutraceuticals. In Food Safety in the 21st Century; Gupta, R.K., Minhas, D., Minhas, S., Eds.; Academic Press: Cambridge, MA, USA, 2017; pp. 491-496. [CrossRef]

2. Sachdeva, V.; Roy, A.; Bharadvaja, N. Current Prospects of Nutraceuticals: A Review. Curr. Pharm. Biotechnol. 2020, 21, 884-896. [CrossRef] [PubMed]

3. Álvarez-Martínez, F.J.; Barrajón-Catalán, E.; Micol, V. Tackling Antibiotic Resistance with Compounds of Natural Origin: A Comprehensive Review. Biomedicines 2020, 8, 405. [CrossRef] [PubMed]

4. Favela-González, K.M.; Hernández-Almanza, A.Y.; De la Fuente-Salcido, N.M. The value of bioactive compounds of cruciferous vegetables (Brassica) as antimicrobials and antioxidants: A review. J. Food Biochem. 2020, 44, e13414. [CrossRef]

5. Vale, A.P.; Santos, J.; Melia, N.; Peixoto, V.; Brito, N.V.; Beatriz, M.; Oliveira, P.P. Phytochemical composition and antimicrobial properties of four varieties of Brassica oleracea sprouts. Food Control 2015, 55, 248-256. [CrossRef]

6. Moreno, D.A.; Carvajal, M.; López-Berenguer, C.; García-Viguera, C. Chemical and biological characterisation of nutraceutical compounds of broccoli. J. Pharm. Biomed. Anal. 2006, 41, 1508-1522. [CrossRef]

7. Kusznierewicz, B.; Bartoszek, A.; Wolska, L.; Drzewiecki, J.; Gorinstein, S.; Namieśnik, J. Partial characterization of white cabbages (Brassica oleracea var. capitata f. alba) from different regions by glucosinolates, bioactive compounds, total antioxidant activities and proteins. LWT Food Sci. Technol. 2008, 41, 1-9. [CrossRef]

8. Kumar, V.; Thankur, A.K.; Barothia, N.D.; Chatterjee, S.S. Therapeutic potentials of Brassica juncea: An overview. CellMed 2011, 1, 2.1-2.16. [CrossRef]

9. Mazumder, A.; Dwivedi, A.; du Plessis, J. Sinigrin and its therapeutic benefits. Molecules 2016, 21, 416. [CrossRef]

10. Egner, P.A.; Chen, J.G.; Wang, J.B.; Wu, Y.; Sun, Y.; Lu, J.H.; Zhu, J.; Zhang, Y.H.; Chen, Y.S.; Friesen, M.D.; et al. Bioavailability of sulforaphane from two broccoli sprout beverages: Results of a short-term, cross-over clinical trial in Qidong, China. Cancer Prev. Res. 2011, 4, 384-395. [CrossRef]

11. Abellán, Á.; Domínguez-Perles, R.; Moreno, D.A.; García-Viguera, C. Sorting out the Value of Cruciferous Sprouts as Sources of Bioactive Compounds for Nutrition and Health. Nutrients 2019, 11, 429. [CrossRef]

12. Aires, A.; Carvalho, R. Rapid separation of indol leglucosinolates in roots of Chinese cabbage (subs. Pekinensis) by high performance liquid chromatography with diode array detection. Int. J. Anal. Chem. 2017, 2017, 5125329. [CrossRef] [PubMed] 
13. Doheny-Adams, T.; Redeker, K.; Kittipol, V.; Bancroft, I.; Hartley, E. Development of an efficient glucosinolate extraction method. Plant Methods 2017, 13, 17. [CrossRef]

14. Ishida, M.; Hara, M.; Fukino, N.; Kakizaki, T.; Morimitzu, Y. Glucosinolate metabolism, functionality and breeding for the improvement of Brassicaceae vegetables. Breed Sci. 2014, 64, 48-59. [CrossRef] [PubMed]

15. Saladino, F.; Bordin, K.; Luciano, F.B.; Franzón, M.F.; Mañes, J.; Meca, G. Antimicrobial Activity of the Glucosinolates. In Glucosinolates; Mérillon, J.M., Ramawat, K., Eds.; Springer: Cham, Switzerland, 2017; pp. 249-274. [CrossRef]

16. Crocoll, C.; Halkier, B.A.; Burow, M. Analysis and quantification of glucosinolates. Curr. Protoc. Plant Biol. 2016, 1, 385-409. [CrossRef]

17. Melchini, A.; Traka, M.H. Biological profile of erucin: A new promising anticancer agent from Cruciferous vegetables. Toxins 2010, 2, 593-612. [CrossRef]

18. Sandoval, M.; Okuhama, N.N.; Angeles, F.M.; Melchor, V.V.; Condezo, L.A.; Lao, J.; Miller, M.J.S. Antioxidant activity of the cruciferous vegetable Maca (Lepidiummeyenii). Food Chem. 2002, 79, 207-213. [CrossRef]

19. Farag, M.A.; Motaal, A.A. Sulforaphane composition, cytotoxic and antioxidant activity of crucifer vegetables. J. Adv. Res. 2010, 1, 65-70. [CrossRef]

20. Morales-López, J.; Centeno-Álvarez, M.; Nieto-Camacho, A.; López, M.G.; Pérez-Hernández, E.; Pérez-Hernández, N.; Fernándo-Martínez, E. Evaluation of antioxidant and hepatoprotective effects of white cabbage essential oil. Pharm. Biol. 2017, 55, 233-241. [CrossRef]

21. Hu, S.-H.; Wang, J.-C.; Kung, H.-F.; Wang, J.-T.; Lee, W.-L.; Yang, Y.-H. Antimicrobial effect of extracts of Cruciferous vegetables. Kaoksiung J. Med. Sci. 2004, 20, 591-599. [CrossRef]

22. Abushouk, A.I.; Ismail, A.; Salem, A.M.A.; Afifi, A.M.; Abdel-Daim, M.M. Cardioprotective mechanisms of phytochemicals against doxorubicin-induced cardiotoxicity. Biomed. Pharmacother. 2017, 90, 935-946. [CrossRef]

23. Manchali, S.; Chidambara Murthy, K.N.; Patil, B.S. Crucial facts about health benefits of popular cruciferous vegetables. J. Funct. Foods 2012, 4, 94-106. [CrossRef]

24. Bătrîna, S.; Corcionivoschi, N.; Jurcoane, S.; Linton, M.; Kelly, C.; Pinkerton, L.; Imbrea, I.M.; Sima, F.; Imbrea, F. Camelina sativa oil can inhibit Campylobacter jejuni but stimulate lactic acid bacteria growth. Rom. Biotechnol. Lett. 2021, 26, 2423-2427. [CrossRef]

25. Brand-Williams, W.; Cuvelier, M.E.; Berset, C. Use of a free radical to evaluate antioxidant activity. LWT Food Sci. Technol. 1995, 28, 25-30. [CrossRef]

26. Ştefănuţ, M.N.; Căta, A.; Pop, R.; Tănasie, C.; Boc, D.; Ienaşcu, I.; Ordodi, V. Anti-hyperglycemic effect of bilberry, blackberry and mulberry ultrasonic extracts on diabetic rats. Plant Foods Hum. Nutr. 2013, 68, 378-384. [CrossRef] [PubMed]

27. Little, T.A. Method validation essentials, limit of blank, limit of detection, and limit of quantitation. BioPharm. Int. 2015, 28 , 48-51.

28. EUCAST-AFST; Arendrup, M.C.; Cuenca-Estrella, M.; Lass-Flörl, C.; Hope, W. EUCAST technical note on the EUCAST definitive document EDef 7.2: Method for the determination of broth dilution minimum inhibitory concentrations of antifungal agents for yeasts EDef 7.2 (EUCAST-AFST). Clin. Microbiol. Infect. 2012, 18, E246-E247. [CrossRef] [PubMed]

29. Clinical and Laboratory Standards Institute. Methods for Dilution Antimicrobial Susceptibility Tests for Bacteria That Grow Aerobically, 11th ed.; M07Ed11; Clinical and Laboratory Standards Institute: Wayne, PA, USA, 2018.

30. Fecker, R.; Buda, V.; Alexa, E.; Avram, S.; Pavel, I.Z.; Muntean, D.; Cocan, I.; Watz, C.; Minda, D.; Dehelean, C.A.; et al. Phytochemical and Biological Screening of Oenotherabiennis, L. Hydroalcoholic Extract. Biomolecules 2020, 10, 818. [CrossRef] [PubMed]

31. Muntean, D.; Licker, M.; Alexa, E.; Popescu, I.; Jianu, C.; Buda, V.; Dehelean, C.A.; Ghiulai, R.; Horhat, F.; Horhat, D.; et al. Evaluation of essential oil obtained from Mentha $\times$ piperita L. against multidrug-resistant strains. Infect. Drug Resist. 2019, 12, 2905-2914. [CrossRef] [PubMed]

32. Buda, V.; Brezoiu, A.M.; Berger, D.; Pavel, I.Z.; Muntean, D.; Minda, D.; Dehelean, C.A.; Stoica, C.; Diaconeasa, Z.; Folescu, R.; et al. Biological Evaluation of Black Chokeberry Extract Free and Embedded in Two Mesoporous Silica-Type Matrices. Pharmaceutics 2020, 12, 838. [CrossRef]

33. Grosser, K.; van Dam, N.M. A straightforward method for glucosinolate extraction and analysis with high-pressure liquid chromatography (HPLC). J. Vis. Exp. 2017, 121, e55425. [CrossRef] [PubMed]

34. Bhandari, S.R.; Jo, J.S.; Lee, J.G. Comparison of Glucosinolate Profiles in Different Tissues of Nine Brassica Crops. Molecules 2015, 20, 15827-15841. [CrossRef]

35. Cataldi, T.R.I.; Lelario, F.; Orlando, D.; Bufo, S.A. Collision-induced dissociation of the A+2 isotope ion facilitates glucosinolates structure elucidation by electrospray with a linear quadrupole ion trap. Anal. Chem. 2010, 82, 5686-5696. [CrossRef] [PubMed]

36. Capriotti, A.L.; Cavaliere, C.; La Barbera, G.; Montone, C.M.; Piovesana, S.; Chiozzi, R.Z.; Laganà, A. Chromatographic column evaluation for untargeted profiling of glucosinolates in cauliflower by means of ultra-high-performance liquid chromatography coupled to high resolution mass spectrometry. Talanta 2018, 179, 792-802. [CrossRef] [PubMed]

37. World Health Organization. Permissible Limits of Heavy Metals in Soil and Plants; WHO: Geneva, Switzerland, 1996.

38. The European Parliament and the Council. Commission Regulation No.1275/2013. Off. J. EU 2013, L328/86.

39. Soengas, P.; Sotelo, T.; Velasco, P.; Cartea, M.E. Antioxidant properties of Brassica vegetables. Funct. Plant Sci. Biotechnol. 2011, 5, 43-55.

40. Cartea, M.E.; Francisco, M.; Soengas, P.; Velasco, P. Phenolic Compounds in Brassica Vegetables. Molecules 2010, 16, 251-280. [CrossRef]

41. Podsedek, A. Natural antioxidants and antioxidant capacity of Brassica vegetables: A review. LWT Food Sci. Technol. 2007, 40,1-11. [CrossRef] 
42. Plumb, G.W.; Lambert, N.; Chambers, S.J.; Wanigatunga, S.; Heaney, R.K.; Plumb, J.A.; Aruoma, O.I.; Halliwell, B.; Miller, N.J.; Williamson, M.; et al. Are whole extracts and purified glucosinolates from cruciferous vegetables antioxidants? Free Rad. Res. 1996, 25, 75-86. [CrossRef]

43. Barillari, J.; Canistro, D.; Paolini, M.; Ferroni, F.; Pedulli, G.F.; Iori, R.; Valgimigli, L. Direct antioxidant activity of purified glucoerucin, the dietary secondary metabolite contained in rocket (Eruca sativa Mill.) seeds and sprouts. J. Agric. Food Chem. 2005, 53, 2475-2482. [CrossRef]

44. Cartea, M.E.; Velasco, P. Glucosinolates in Brassica foods: Bioavailability in food and significance for human health. Phytochem. Rev. 2008, 7, 213-229. [CrossRef]

45. Cartea, M.E.; Velasco, P.; Sara Obregón, S.; Padilla, G.; de Haro, A. Seasonal variation in glucosinolate content in Brassica oleracea crops grown in northwestern Spain. Phytochemistry 2008, 69, 403-410. [CrossRef] [PubMed]

46. Hwang, I.M.; Park, B.; Dang, Y.M.; Kim, S.-Y.; Seo, H.Y. Simultaneous direct determination of 15 glucosinolates in eight Brassica species by UHPLC-Q-Orbitrap-MS. Food Chem. 2019, 282, 127-133. [CrossRef]

47. Tian, Q.; Rosselot, R.A.; Schwartz, S.J. Quantitative determination of intact glucosinolatesin broccoli, broccoli sprouts, Brussels sprouts, and cauliflowerby high-performance liquid chromatography-electrosprayionization-tandem mass spectrometry. Anal. Biochem. 2005, 343, 93-99. [CrossRef]

48. Vicas, S.I.; Teusdea, A.C.; Carbunar, M.; Socaci, S.A.; Socaciu, C. Glucosinolates Profile and Antioxidant Capacity of Romanian Brassica Vegetables Obtained by Organic and Conventional Agricultural Practices. Plant Foods Hum. Nutr. 2013, 68, 313-321. [CrossRef] [PubMed]

49. Cabello-Hurtado, F.; Gicquel, M.; Esnault, M.-A. Evaluation of the antioxidant potential of cauliflower (Brassica oleracea) from aglucosinolate content perspective. Food Chem. 2012, 132, 1003-1009. [CrossRef]

50. Kim, S.-J.; Uddin, M.R.; Park, S.U. Glucosinolate accumulation in three important radish (Raphanussativus) cultivars. Aust. J. Crop Sci. 2013, 7, 1843-1847.

51. Ediage, E.N.; Di Mavungu, J.D.; Scippo, M.L.; Schneider, Y.J.; Larondelle, Y.; Callebaut, A.; Robbens, J.; Van Peteghem, C.; De Saeger, S. Screening, identification and quantification of glucosinolates in black radish (Raphanus sativus L. niger) based dietary supplements using liquid chromatography coupled with a photodiode array and liquid chromatography -mass spectrometry. J. Chromatogr. A 2011, 1218, 4395-4405. [CrossRef] [PubMed]

52. Melegari, G.; Iseppi, R.; Mariani, M.; Giuliani, E.; Caciagli, V.; Bertellini, E.; Messi, P.; Barbieri, A. Keyboard Contamination in Intensive Care Unit: Is Cleaning Enough? Prospective Research of In Situ Effectiveness of a Tea Tree Oil (KTEO) Film. In Advances in Microbiology, Infectious Diseases and Public Health; Donelli, G., Ed.; Advances in Microbiology, Infectious Diseases and Public Health; Springer: Cham, Switzerland, 2021; Volume 15, pp. 91-102.

53. Man, A.; Santacroce, L.; Jacob, R.; Mare, A.; Man, L. Antimicrobial activity of six essential oils against a group of human pathogens: A comparative study. Pathogens 2019, 8, 15. [CrossRef]

54. Brabban, A.D.; Edwards, C. The effects of glucosinolates and their hydrolysis products on microbial growth. J. Appl. Bacteriol. 1995, 79, 171-177. [CrossRef]

55. Kyung, K.H.; Fleming, H.P. Antimicrobial activity of sulfur compounds derived from cabbage. J. Food Prot. 1997, 60, 67-71. [CrossRef]

56. Dias, C.; Aires, A.; Saavedra, M.J. Antimicrobial activity of isothiocyanates from cruciferous plants against methicillin-resistant Staphylococcus aureus (MRSA). Int. J. Mol. Sci. 2014, 15, 19552-19561. [CrossRef]

57. Jadoun, J.; Yazbak, A.; Rushrush, S.; Rudy, A.; Azaizeh, H. Identification of a New Antibacterial Sulfur Compound from Raphanus sativus Seeds. Evid. Based Complement. Alternat. Med. 2016, 2016, 9271285. [CrossRef] [PubMed]

58. Stojković, D.; Smiljković, M.; Nikolić, M.; Živković, J.; Soković, M. Sensitivity of multiresistant bacteria and methicillin-resistant Staphylococcus aureus to ethanolic root extract of Raphanus sativus. Lek. Sirovine 2018, 38, 35-38. [CrossRef]

59. Rubab, M.; Chelliah, R.; Saravanakumar, K.; Kim, J.-R.; Yoo, D.; Wang, M.-H.; Oh, D.-H. Phytochemical characterization, and antioxidant and antimicrobial activities of white cabbage extract on the quality and shelf life of raw beef during refrigerated storage. RSC Adv. 2020, 10, 41430-41442. [CrossRef]

60. Aires, A.; Mota, V.R.; Saavedra, M.J.; Monteiro, A.A.; Simões, M.; Rosa, E.A.; Bennett, R.N. Initial in vitro evaluations of the antibacterial activities of glucosinolate enzymatic hydrolysis products against plant pathogenic bacteria. J. Appl. Microbiol. 2009, 106, 2096-2105. [CrossRef] [PubMed]

61. Ibáñez-Peinado, D.; Pina-Pérez, C.; García-Carrión, G.; Martínez, A.; Rodrigo, D. In vivo antimicrobial activity assessment of a cauliflower by-product extract against Salmonella Typhimurium. Front. Sustain. Food Syst. 2020, 4, 8. [CrossRef]

62. Palaniappan, K.; Holley, R.A. Use of natural antimicrobials to increase antibiotic susceptibility of drug resistant bacteria. Int. J. Food Microbiol. 2010, 140, 164-168. [CrossRef]

63. Brown, K.K.; Hampton, M.B. Biological targets of isothiocyanates. Biochim. Biophys. Acta 2011, 1810, 888-894. [CrossRef]

64. Luciano, F.B.; Hosseinian, F.S.; Beta, T.; Holley, R.A. Effect of free-SH containing compounds on allylisothiocyanate antimicrobial activity against Escherichia coli O157:H7. J. Food Sci. 2008, 73, M214-M220. [CrossRef]

65. Borges, A.; Abreu, A.C.; Ferreira, C.; Saavedra, M.J.; Simões, L.C.; Simões, M. Antibacterial activity and mode of action of selected glucosinolate hydrolysis products against bacterial pathogens. J. Food Sci. Technol. 2015, 52, 4737-4748. [CrossRef]

66. Zampini, I.C.; Cuello, S.; Alberto, M.R.; Ordonez, R.M.; Almeida, R.D.; Solorzano, E.; Isla, M.I. Antimicrobial activity of selected plant species from "the Argentine Puna" against sensitive and multi-resistant bacteria. J. Ethnopharmacol. 2009, 124, 499-505. [CrossRef] [PubMed] 